\title{
MIT-Skywalker: considerations on the Design of a Body Weight Support System
}

Rogério Sales Gonçalves ${ }^{1,2^{*}}$ and Hermano Igo Krebs $3,4,5,6,7,8$

\begin{abstract}
Background: To provide body weight support during walking and balance training, one can employ two distinct embodiments: support through a harness hanging from an overhead system or support through a saddle/seat type. This paper presents a comparison of these two approaches. Ultimately, this comparison determined our selection of the body weight support system employed in the MIT-Skywalker, a robotic device developed for the rehabilitation/habilitation of gait and balance after a neurological injury.

Method: Here we will summarize our results with eight healthy subjects walking on the treadmill without any support, with $30 \%$ unloading supported by a harness hanging from an overhead system, and with a saddle/seatlike support system. We compared the center of mass as well as vertical and mediolateral trunk displacements across different walking speeds and support.

Results: The bicycle/saddle system had the highest values for the mediolateral inclination, while the overhead harness body weight support showed the lowest values at all speeds. The differences were statistically significant.

Conclusion: We selected the bicycle/saddle system for the MIT-Skywalker. It allows faster don-and-doff, better centers the patient to the split treadmill, and allows all forms of training. The overhead harness body weight support might be adequate for rhythmic walking training but limits any potential for balance training.
\end{abstract}

Keywords: Rehabilitation robotics, Lower extremity, Gait, Balance, Body weight support system

\section{Background}

Presently an estimated 6.6 million Americans have survived a stroke [1]. Projections from the American Heart Association suggest that this number will be swelled by an additional 3.4 million people by 2030 [1] and the majority of stroke survivors will experience some motor deficits [2, 3]. Although there are a few treatment alternatives to improve cerebral perfusion and neuroprotection after stroke $[2,4]$, the only way, at this time, for neuro-recovery to ameliorate and reduce the consequences of central nervous system injury is through physical or occupational therapy delivered by clinicians and potentially augmented by robotic tools $[4,5]$.

\footnotetext{
*Correspondence: rsgoncalves@ufu.br

${ }^{1}$ Federal University of Uberlândia/Brazil, School of Mechanical Engineering, Av. João Naves de Ávila 2121 Campus Santa Monica CX 593, Uberlândia, MG CEP 38408-100, Brazil

${ }^{2}$ Mechanical Engineering Department, The Eric P. and Evelyn E. Newman Laboratory for Biomechanics and Human Rehabilitation, Massachusetts Institute of Technology - MIT, Boston, USA

Full list of author information is available at the end of the article
}

Different methods of gait rehabilitation have been proposed over the years and body weight supported treadmill training (BWSTT) emerged as the approach of choice in early 2000 [6-9]. Patients were suspended in a body weight support harness over a treadmill, while two or sometimes three therapists assisted the patient: one or two sitting adjacent to the paretic leg(s) in order to provide movement assistance, and the other therapist standing behind the patient to shift body weight [6-9]. Hesse et al. showed that treadmill training with partial body weight support compared favorably to the then prevalent Bobath method in improving both gait ability and walking velocity in stroke patients [10]. The Bobath method attempts to restore more physiological gait pattern by applying tone-inhibiting exercises and motor tasks while patient is in a seated, standing or lying position [11]. BWSTT became the "gold standard" of gait rehabilitation with a meta-analysis of 21 randomized controlled trials (RCTs), suggesting that both gait speed and walking distance improved after BSWTT [12]. 
Increased brain activity has been observed during BWSTT in ANIRS [13] and after BWSTT in fMRI scans of stroke patients making ankle pointing movements, implying that the intervention went beyond adaptation and truly has neuro-recovery potential [14].

As clinicians began to fully incorporate the assumption that body weight supported treadmill training (BWSTT) delivered by 2 or 3 therapists per stroke patient was indeed "best practice," automating BWSTT appeared to be the next logical step. Engineers developed robotic tools to replace this grueling, laborious, and ergonomically challenging approach. The devices can be classified into two main types: exoskeletons [15-17] and end-effector robots [18-21]. Both of these forms have shown promise in small pilot studies [22-26]. Yet when these robots were compared to usual care as practiced in the US in both subacute and chronic stroke populations, results failed to show the expected efficacy of the intervention [27, 28].

Furthermore, contrary to its clinical proponents, an $\mathrm{NIH}$-sponsored randomized clinical trial demonstrated that the BWSTT did not lead to results superior to those from a much simpler and basic kitchen-and-sink home program that focused on only strength and balance training $[29,30]$. This study, known as LEAPS, a 2011 Randomized Control Trial with over 400 stroke patients, highlighted that the goal of rehabilitation robotics cannot be to simply automate current rehabilitation practices. For the most part, automation lacks an evidential basis: a scientific basis is needed for the development of effective robotic therapy.

Knowledge of human sensorimotor control has matured to the point where a fundamental theory of walking is within reach. To enable the application of robotics to assist walking, we developed a competent model of human walking. By "competent model" we mean that it may only be a first approximation of a fundamental theory, but it is good enough to improve the design of robots and regimens for lower extremity therapy. In this working model, we considered walking in a wide range of realistic scenarios. Humans walk easily in diverse environments, including slopes, stairs, and uneven surfaces despite slow muscles, long neural communication delays and noise. Humans initiate and stop movements as well as change directions and transition between postures. Humans react to unexpected perturbations successfully. To accommodate real-life walking with all its variations, we propose a modeling approach that on a task-level encompasses discrete, rhythmic movements, and balance, which are decomposed into the dynamic primitives of submovements, oscillations, and mechanical impedances. An outline of this theory is presented in [31-36].

To enable the translation of this model to assist walking, we developed the MIT-Skywalker. The MITSkywalker is distinct from any of the existing rehabilitation robotic devices for gait [30,37]. A key aspect of the design is the body weight support system. This paper presents some of the considerations and the results from a study of eight healthy subjects that guided us on the selection of the preferred support method. Here we will summarize our results on the displacement of the center of mass and the trunk under three conditions: subjects walking on the treadmill without any support, with $30 \%$ unloading supported by a harness hanging from an overhead system, and with a saddle/seat like support system.

\section{MIT-Skywalker}

The MIT-Skywalker embodies the concept of passive walker in rehabilitation. The MIT-Skywalker walking system is shown in Fig. 1. The system has five active degrees of freedom: full system rotation in the frontal plane (a), independent treadmill actuation of both belts (b) and independent sagittal plane rotation of each treadmill about its front roller (c). Two of the drives are mirrored across the bisecting sagittal plane of the machine, resulting in three unique control systems drives [29].

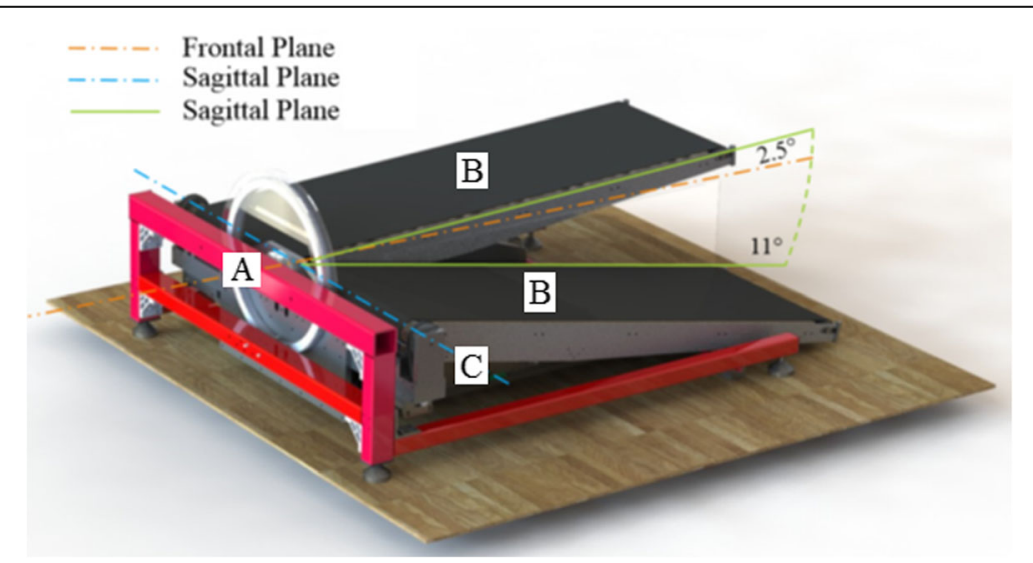

Fig. 1 MIT-Skywalker 
The MIT-Skywalker has a vision system to provide real time estimates of the angle of the thigh and shin so as to determine the posture and position of the patient (for additional details see $[29,30,37,38]$ ). Figure 2 shows the principle of function of the MIT-Skywalker. In traditional BWSTT, Fig. 2(a), the leg supports the trunk while it moves backward relative to the trunk during the stance phase; at toe-off the support is shifted, the ankle completes a propulsive plantarflexion movement, and initiates a dorsiflexion movement to clear the ground initiating the swing phase. The walking surface is necessary during the stance phase, but it inhibits the leg during the swing phase and requires clearing the surface and propelling the leg forward. In the MIT-Skywalker, Fig. 2(b), the split treadmill moves the patient's foot to the toe-off position. Once the vision acquisition system recognizes the heel $Z$-position has reached a minimum (patient-initiated swing phase), Fig. 2(b), the track is dropped, allowing the foot to swing forward freely for another step partially assisted by gravity (pendulum) and partially by patient's effort.

\section{Body weight support system}

In addition to the MIT-Skywalker moving platform, we considered two forms of actuated body weight support system: a harness hanging from an overhead system and a saddle/bicycle seat supporting from underneath.

The harness system hanging from an overhead pontoon includes a commercial harness and the ability to unload and record the vertical displacement during training. The saddle/bicycle seat system includes a bicycle seat, a lap belt, and a loose fitting chest vest as shown in Fig. 3. The bicycle seat is mounted onto a shaft that is able to rotate in the transverse plane, but is restrained in other rotational DOFs by cylindrical linear bearings. A spring and linear potentiometer are employed to allow vertical displacement and to estimate the unloading and to record the vertical displacement during training. The system's linear actuator sets the height of the BWS, thereby determining the percent of weight unloading. Note that the chest harness is used for safety and to "catch" the subject, thus preventing falls. The complete details of saddle/bicycle seat BWS can be found in $[30,37]$.

\section{On the use of Microsoft Kinect V2}

The Microsoft ${ }^{\prime \prime}$ Kinect $^{\circ}$ V2 (Kinect) is a low-cost markerless motion caption system designed for the Microsoft Xbox". The Kinect has shown promise in clinical/ biomechanics studies [39-47]. The version V2 was released in 2014 with improved depth and image hardware. It can track 3-D movement through its depth sensor and output the location of 25 joints in 3-D space at $30 \mathrm{~Hz}$ [48]. Previous studies [39, 40] showed the validity of the Kinect sensor to estimate the center of mass $(\mathrm{COM})$ and we employed this approach in studying the different forms of body weight support. The COM location depends on body posture and on subject's specific physical features. Typically, when the subject is standing upright (normal pose), the COM is located approximately at the center of the torso of the body [49]. Thus this paper uses the Kinect mid-spine joint as a coarse approximation of the COM during the gait cycle. Figure 4 shows the MIT-Skywalker and the placement of the Kinect [50]. The Kinect sensor was placed in front of the MIT-Skywalker and it recorded the 25 joint locations with software Kinect Studio v2.0. Figure 7(a) shows the 25 joints. The Kinect allows us to obtain the Cartesian position and the orientation of each joint. A complete joint description can be found in [45]. We used an open-source software [51] to extract/split the color and

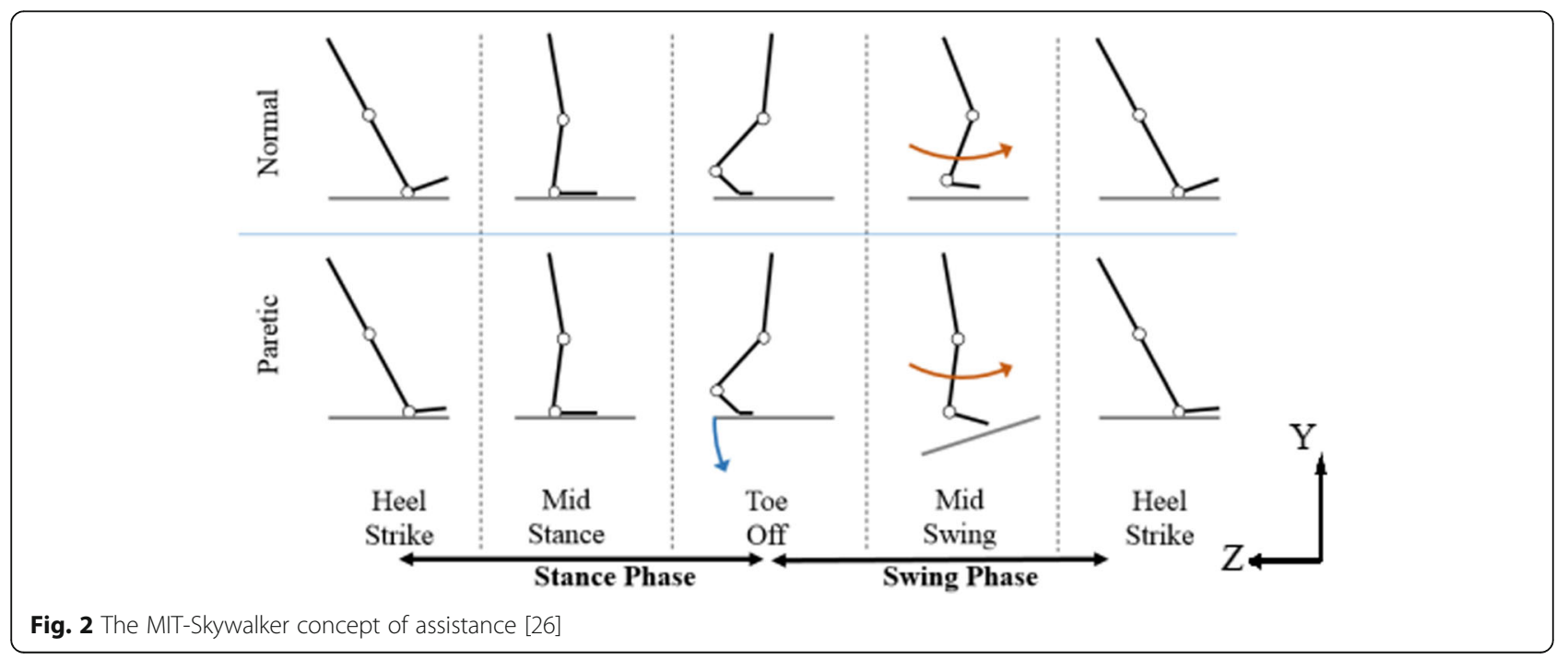




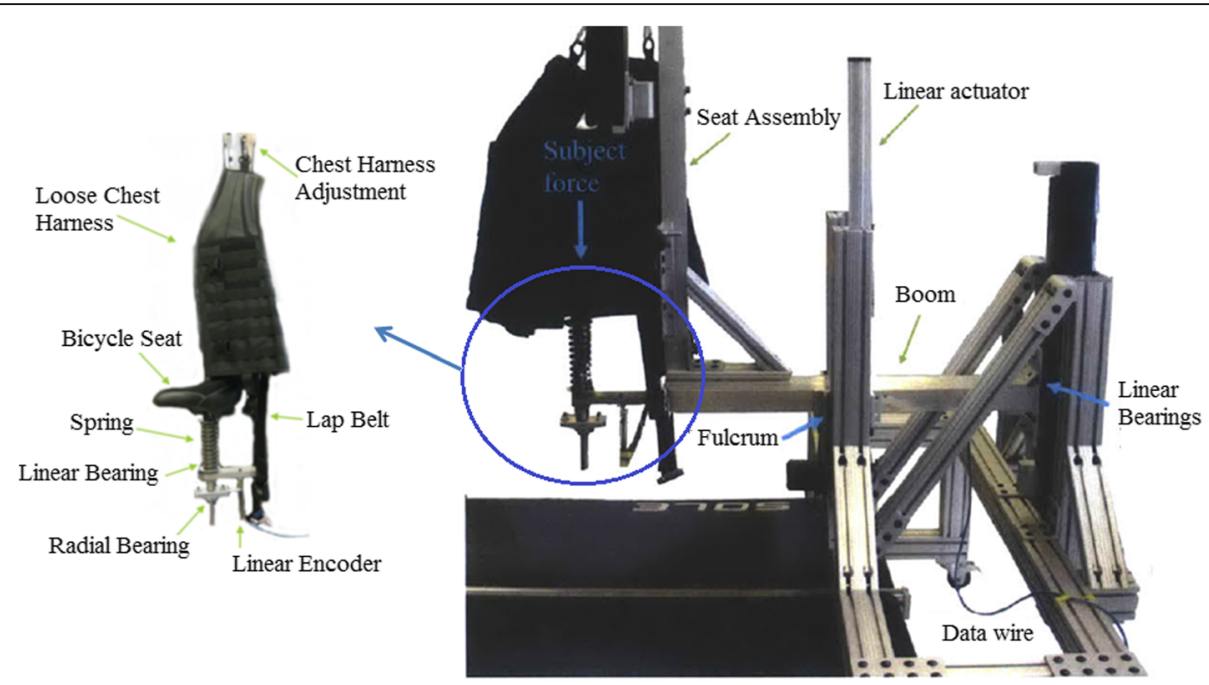

Fig. 3 The MIT-Skywalker body weight support device

depth image as well as the skeleton data. Data was analyzed using the Matlab $^{\circ} 2015$.

\section{Method}

\section{Participants}

Eight young adults [ 4 women and 4 males, age: 22.25 $( \pm 3.02)$ years, height: $1.68( \pm 0.10) \mathrm{m}$, mass: $67.4( \pm 11.91)$ $\mathrm{kg}$ ] without any record of musculoskeletal or neurological disorder volunteered to participate. The study was approved by the MIT Committee on the Use of Humans as Experimental Subjects (COUHES).

\section{Experimental setup}

Prior to the trials, subjects were given a brief training/ explanation session on the MIT-Skywalker to ensure they were acclimated to the device. The trial itself was

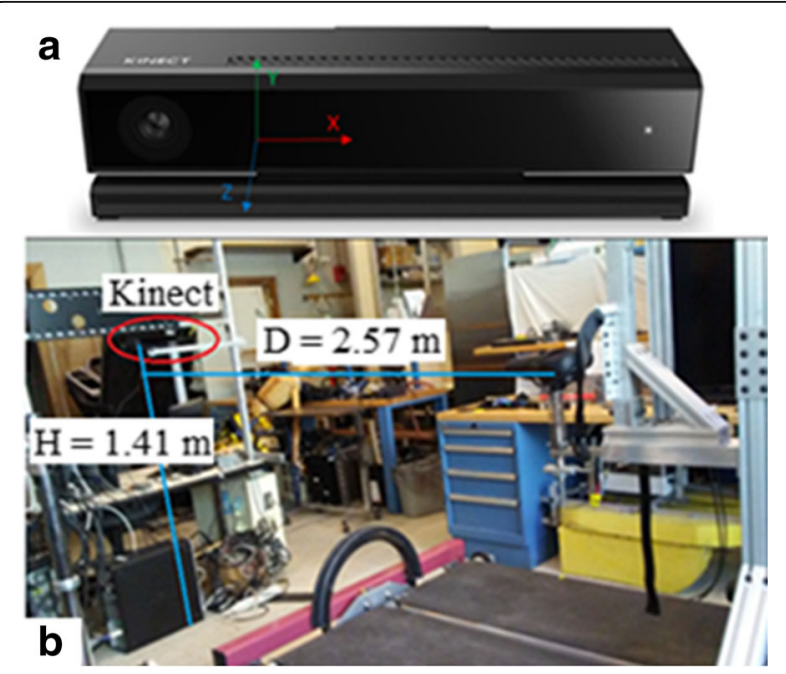

Fig. 4 Kinect position and the reference system organized as a $3 \times 3$ matrix. Three blocks were performed by the subjects walking on the MIT-Skywalker at three different walking speeds, corresponding to past experience with persons who had an impairment $(\mathrm{v} 1=0.223 \mathrm{~m} / \mathrm{s}, \mathrm{v} 2=0.447 \mathrm{~m} / \mathrm{s}$, and $\mathrm{v} 3=0.671 \mathrm{~m} / \mathrm{s})$ and employing three support conditions: no BWS, overhead BWS, and the saddle/bicycle seat BWS (see Figs. 5 and 6). Each block lasted for $3 \mathrm{~min}$. During the first minute subjects adapted to the selected speed. We acquired the data in the subsequent $2 \mathrm{~min}$ and the speed presentation was block-randomized. To check whether subjects were adapted after the familiarization session, we compared the amplitude of the mediolateral displacement at the beginning, middle and the end of the 2-min data acquisition period and tested for any differences in amplitude. For the two BWS conditions, the system was adjusted to unload $30 \%$ of the subject's weight. The overhead BWS included a scale and a linear actuator (see Figs. 3 and 6).

For each block, we captured all the subject's steps. For each step, we identified the maximum and minimum value of the mid- and shoulder-spine markers from the Kinect as shown in Fig. 7(a). We considered the midspine as an approximation of the human center of mass $(\mathrm{COM})$. In addition, we considered the mediolateral and vertical displacement of the shoulder-spine marker [see Fig. 7(b)]. We utilized the color image to identify all steps. We excluded strides that lasted less than 10 frames.

\section{Statistical analysis}

We compared the COM, as well as vertical and mediolateral displacements across different walking speeds and support using one-way ANOVAs and t-test. Before applying the ANOVA and the t-test, we checked for 

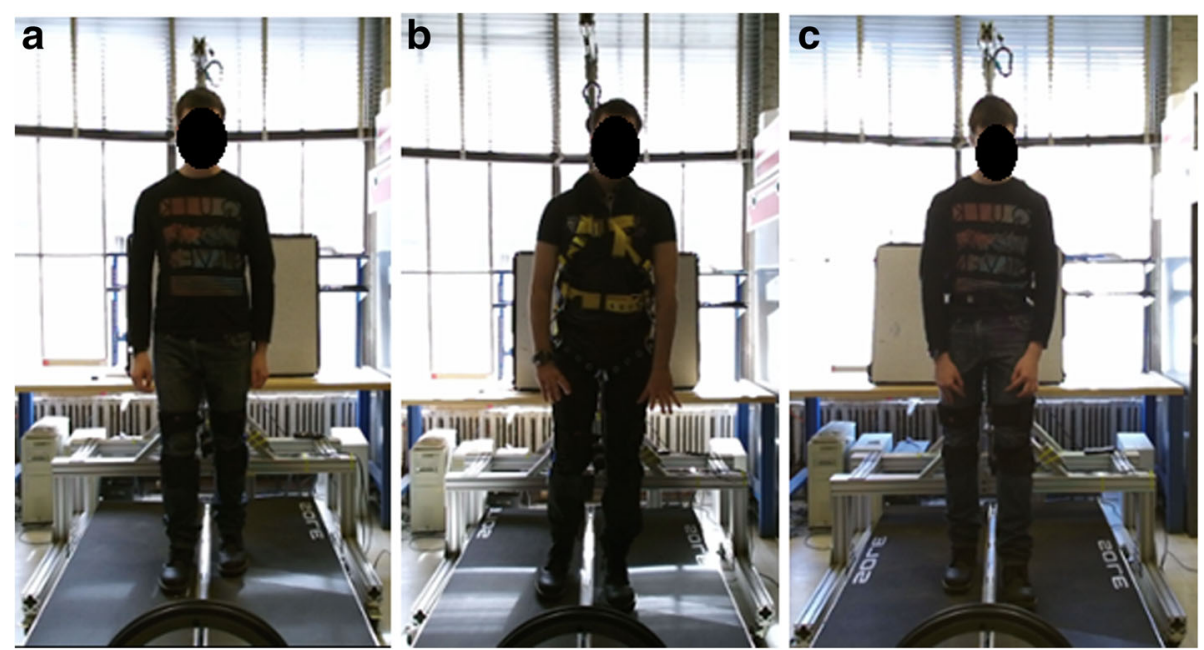

Fig. 5 Testing apparatus on the MIT-Skywalker. (a) no BWS; (b) overhead harness; and (c) saddle/bicycle seat

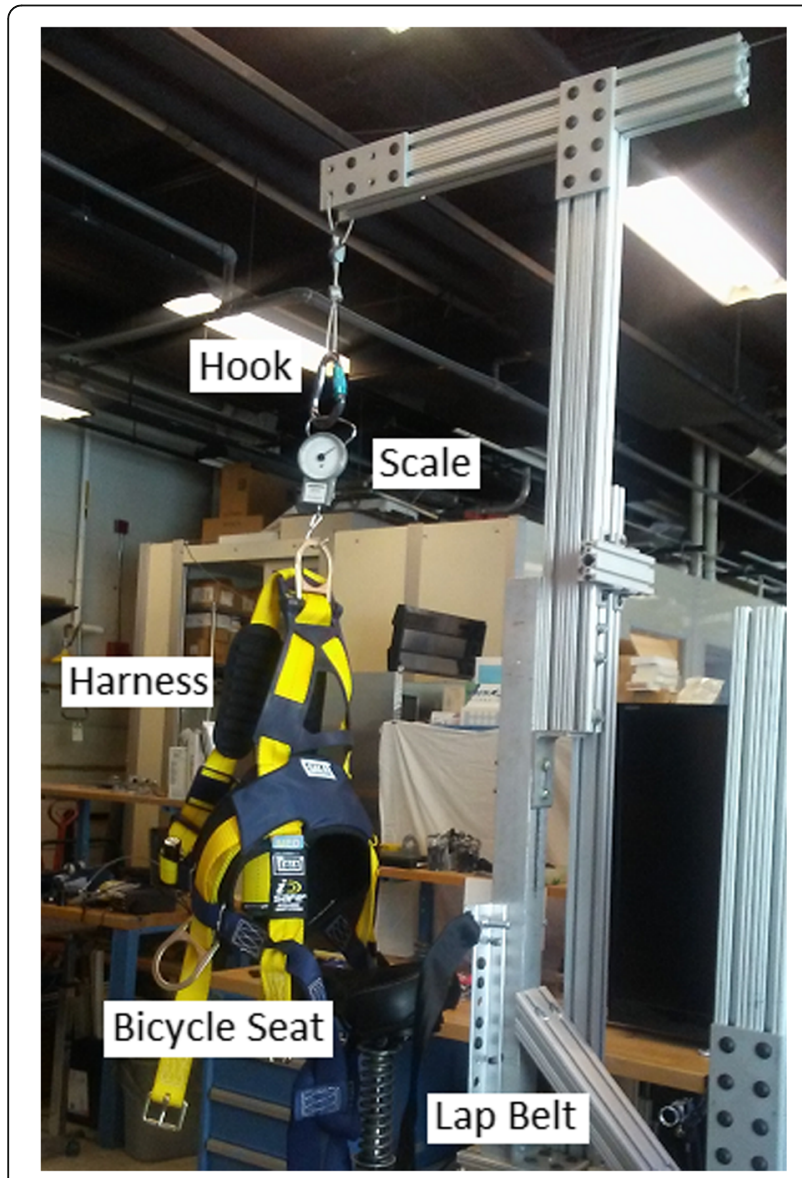

Fig. 6 Experimental setup to compare different BWS normality of the data thru a Jarque-Bera test. It confirmed the normality of the data to a significant level of 0.01. We employed ANOVAs to compare different speeds and support systems. The t-test was employed to compare two different speeds with the same support system. In these tests pij represents the $p$-value between the speed $i$ and $j$. The significance level was set to 0.05 . The asterisk in the Tables indicates statistical significance.

\section{Results}

Tables 1, 2, 3 summarize the results. The coordinates $X$ (mediolateral displacement) and $Y$ (vertical displacement) represent the coordinates of mid-spine. The coordinates $X 1$ (mediolateral displacement) and $Y 1$ (vertical displacement) represent the coordinates of shoulderspine. The mid-spine is identified as the COM and the shoulder-spine as the body trunk. There were statistically significant differences for the COM and mediolateral displacements in the "No BWS" condition with the exception of vertical body case $v 1$ vs $v 2$. There were statistical differences for the COM and body mediolateral displacements for Overhead BWS in cases: $v 2$ vs $v 3$ and $v 1$ vs $v 3$. Significant values were found in the cases $v 1$ vs v2 (COM vertical displacements) and $v 1$ vs $v 3$ (COM vertical displacements and body vertical displacement). For the bicycle/saddle seat, the COM and body mediolateral displacements were statistically significant.

\section{Discussion}

The aim of the current study is to evaluate two forms of body weight support systems for potential use in the MIT-Skywalker. As walking speed increases in healthy subjects walking without a BWS, the vertical displacement of COM displacement in frontal plane increases. This result is consistent with previous work comparing 

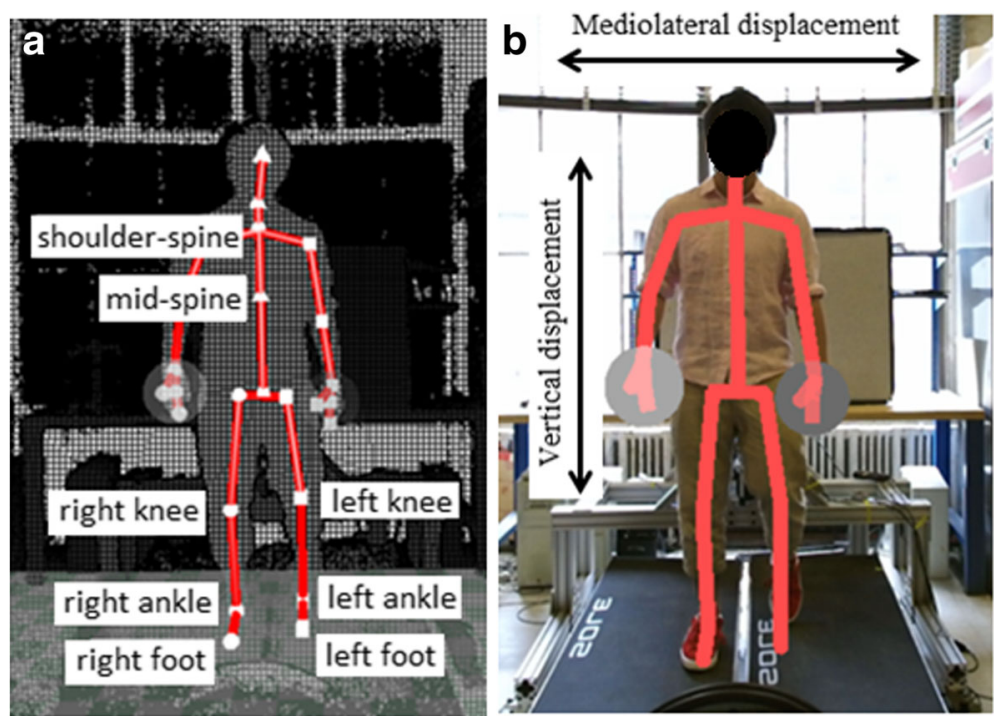

Fig. 7 (a) The identified joints by the Kinect sensor; (b) color image with skeleton and the mediolateral and vertical displacement

the effect of walking speed on COM displacement [52]. We and others observed similar behavior when employing the overhead harness system [53]. That is not case when employing the bicycle/saddle system which is mounted on a spring that limits vertical displacement.

Furthermore, as walking speed increased we observed a decrease of the mediolateral displacement for all cases. The $X_{C O M}$ displacement was large at slow speeds and decreased at faster walking speeds. For individuals with gait pathology, the increased $X_{C O M}$ displacement at slow speed may indicate additional balancing challenges and we speculate on whether one might gain additional benefits when training at low speeds (see Tables 1, 2, 3). To walk upright, bipeds need to activate different mechanisms of balance and these may be affected due to neurological injuries and aging [30,54]. Balance training has been shown to reduce postural asymmetry associated with hemiparesis and was a part of the home-based protocol in the LEAPS study [31]. Furthermore, in the feasibility study of the MIT-Skywalker employing the bicycle/saddle support [30,37], three patients with very different levels of impairment showed substantial improvement on the Berg Balance Test after a one-month study [30]. These initial results were very promising [30] and we plan to commence a larger set of clinical studies to determine whether our training approach with the MIT-Skywalker and its bicycle/saddle support leads to superior results as compared to usual care.

Figure 8 shows a graphical comparison of performance at three different speeds in different types of BWS. $\Delta X_{C O M}$ and $\Delta X 1_{S}$ represent the mediolateral range displacement for the mid-spine and shoulder-spine markers, $\triangle Y_{C O M}$ and $\triangle Y 1_{S}$ represent the vertical range displacement for the same joints, $H$ represents the mean distance of the mid-spine and shoulder-spine for all subjects, and $\phi$ represents the inclination of the trunk.

Note that when using the overhead harness, the trunk has the smallest inclination at all the speeds, Fig. 8. Indeed, the overhead harness imposes a major constraint for trunk inclination. On the contrary, the bicycle/saddle system has the largest inclination which affords balance training. Furthermore, in $[54,55]$ it was shown that trunk exercises performed on an unstable surface improved the trunk muscle activation, postural control, and the gait speed in patients with stroke. There was further improvement observed in acute stroke involving trunk control and functional balance when using a dynamic surface (physio ball) compared to results from the

Table 1 No BWS condition. ${ }^{* *}$ ANOVA and * t-test significance $(p<0.05)$

\begin{tabular}{|c|c|c|c|c|c|c|c|c|c|}
\hline No BWS & $v 1$ & & v2 & & v3 & & t-test $(p)$ & & \\
\hline COM range $(\mathrm{cm})$ & mean & std & mean & Std & mean & std & v1 vs V2 & v2 vs v3 & V1 Vs V3 \\
\hline$x^{* *}$ & 11.11 & 2.01 & 9.11 & 1.50 & 7.70 & 1.71 & $0.0032^{*}$ & $0.0218^{*}$ & $3.2067 e^{-04^{*}}$ \\
\hline$Y^{* *}$ & 1.03 & 0.22 & 1.40 & 0.30 & 1.81 & 0.39 & $0.0063^{*}$ & $0.0032^{*}$ & $0.0015^{*}$ \\
\hline Body range $(\mathrm{cm})$ & mean & std & mean & Std & mean & std & V1 vs V2 & v2 vs v3 & V1 vs V3 \\
\hline$X 1^{* *}$ & 12.64 & 2.50 & 10.19 & 1.85 & 8.33 & 1.97 & $0.0038^{*}$ & $0.0114^{*}$ & $5.1190 \mathrm{e}^{-05^{*}}$ \\
\hline$Y 1^{* *}$ & 1.11 & 0.26 & 1.41 & 0.30 & 1.80 & 0.39 & 0.0582 & $0.0079^{*}$ & $0.0052^{*}$ \\
\hline
\end{tabular}


Table 2 Overhead BWS harness condition ** ANOVA and * t-test significance $(p<0.05)$

\begin{tabular}{llllllllll}
\hline No BWS & v1 & \multicolumn{3}{c}{ v2 } & \multicolumn{5}{c}{ t-test $(p)$} \\
\hline COM range $(\mathrm{cm})$ & mean & std & mean & Std & mean & std & v1 vs v2 & v2 vs v3 & v1 vs v3 \\
X & 9.12 & 1.75 & 8.33 & 2.19 & 6.96 & 2.00 & 0.1358 & $0.0111^{*}$ & $0.0171^{*}$ \\
Y & 0.76 & 0.20 & 1.03 & 0.32 & 1.09 & 0.35 & $0.0384^{*}$ & 0.1580 & $0.0275^{*}$ \\
Body range (cm) & mean & std & mean & Std & mean & std & v1 vs v2 & v2 vs v3 & v1 vs v3 \\
X1 & 9.36 & 2.02 & 8.75 & 2.67 & 7.32 & 2.41 & 0.2021 & $0.0152^{*}$ & $0.0204^{*}$ \\
Y1 & 0.86 & 0.23 & 1.11 & 0.41 & 1.14 & 0.37 & 0.1164 & 0.6357 & $0.0479^{*}$ \\
\hline
\end{tabular}

same exercises being performed on a static surface (physio plinth) [56]. The authors suggested that dynamic practice leads to increased muscle activity with increased demands on postural control, voluntary trunk movements and an increased response to postural perturbations [56, 57].

In the reference [58], it was shown that trunkfunctional assessment post-stroke is important as a requirement for predicting the probable clinical outcome of the patient with stroke and in designing an effective rehabilitation protocol. In the reference [59], 30 post stroke patients were divided into two groups. Group A (experimental group) received trunk rehabilitation, balance training and conventional physiotherapy; Group B (control group) received only conventional physiotherapy. The experimental group demonstrated additional improvements in the trunk impairment scale, Berg balance scale, gait speed, and cadence post intervention as compared to the control group. Swinnen et al. [60] analyzed the three dimensional movements of the trunk in healthy persons during walking on a treadmill with different levels of BWS and concluded that, compared with $0 \%$ BWS, the lateral flexion of the trunk on the pelvis decreased significantly at 10 to $50 \%$ BWS.

Individuals with gait disturbances due to limb loss, neuromuscular pathology, vestibular dysfunction, stroke, or aging elderly have reduced gait speed [57, 61]. As discussed earlier at slow gait speeds, there is an increase in the mediolateral COM motion which increases demand on balance traits [41]. In previous work with the MITSkywalker [29, 37], we tested the effect of the bicycle/ saddle BWSS on a healthy subject up to $50 \%$ unloading. The bicycle/saddle system had a small effect on the kinematics, showing a slightly decreased knee angle. Without the seat, the swing phase initiates later. The use of the seat limited the hip angle [37]. In a recent study [59], we evaluated different shapes of seats to assess this limitation. Results with 10 healthy subjects demonstrated a reduction of $31 \%$ in hip flexion when using the seat. There was no statistically significant change in hip extension. To address this limitation, we recently tested an alternate bicycle/saddle seat and that restricted the hip flexion by only $19 \%$. No statistical difference was found in the degree of pelvic rotation with the new seat (Gonçalves RS, et al.: MIT-Skywalker: evaluating comfort of bicycle/saddle seat, 15th IEEE international conference on rehabilitation robotics, unpublished).

Different research groups studied the influence of an overhead BWS on normal human gait [62-64]. Finch and colleagues found on 10 healthy subjects walking on a treadmill that the amplitude of movement of hip and knee decrease with the use of an overhead harness [62]. They speculated that the harness could limit the vertical displacement of the body, matching our results (see Fig. 8 smaller vertical displacement). Fischer showed that the use of the Biodex BWS had sizeable reductions in lower joint kinematics and kinetics in healthy subjects with increased unloading during over ground gait. The difference between the "no harness" and 30\% unloading was 27.3\% in the hip flexion [63]. Sousa demonstrated a decrease in the range of hip motion with $30 \%$ overhead BWS in stroke subjects during over ground walking [64]. One might suggest that an overhead BWS unfavorably influences balance training due to its pendulum-like behavior $[30,65,66]$. The use of the bicycle/saddle offsets the force just below the body's center of mass,

Table 3 Saddle/Bicycle seat BWS condition. ${ }^{* *}$ ANOVA and * t-test significance $(p<0.05)$

\begin{tabular}{|c|c|c|c|c|c|c|c|c|c|}
\hline No BWS & v1 & & v2 & & v3 & & t-test $(p)$ & & \\
\hline COM range $(\mathrm{cm})$ & mean & std & mean & std & mean & std & V1 vs V2 & v2 vs v3 & v1 vs v3 \\
\hline$X^{* *}$ & 3.77 & 0.86 & 2.97 & 0.90 & 2.22 & 0.46 & $0.0029^{*}$ & $0.0173^{*}$ & $0.0014^{*}$ \\
\hline Y & 0.67 & 1.09 & 0.70 & 0.15 & 0.68 & 0.14 & 0.6189 & 0.7260 & 0.7872 \\
\hline Body range $(\mathrm{cm})$ & mean & std & mean & std & mean & std & v1 vs v2 & v2 vs v3 & v1 vs v3 \\
\hline$X 1^{* *}$ & 5.93 & 1.57 & 4.74 & 1.56 & 3.59 & 0.72 & $0.0101^{*}$ & $0.0446^{*}$ & $0.0038^{*}$ \\
\hline Y1 & 0.82 & 0.18 & 0.78 & 0.15 & 0.81 & 0.21 & 0.6045 & 0.6485 & 0.9285 \\
\hline
\end{tabular}




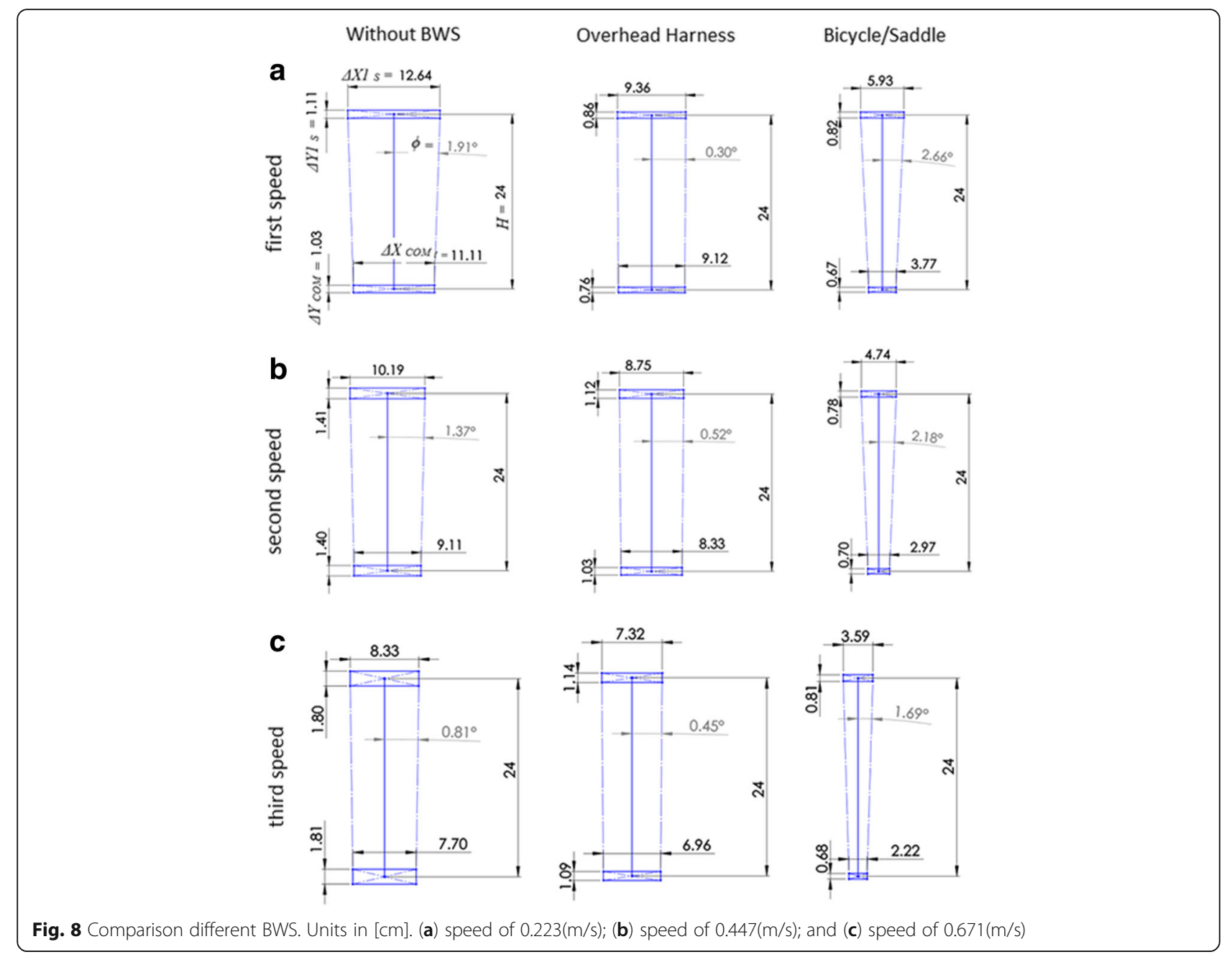

preserving the inverted pendulum behavior [30]. Furthermore, Kataoka and colleagues found on 6 healthy subjects walking on an instrumented treadmill (ITR5018, Bertec Corp, USA) that the ground reaction force profile employing a bicycle/saddle seat resembled the two peak profiles of "no harness" condition, while the overhead BWS profile was markedly distinct with a single peak [67]. In summary, a literature comparison on the impact of the overhead harness system and the bicycle/saddle on the hip joint kinematics showed a similar influence [29, 37, 62-64]. Of course there are more sophisticated smart versions of overhead BWS like Zero$\mathrm{G}$ and FLOAT but those are not inexpensive $[65,68]$.

The bicycle/saddle system has additional advantages. In addition to affording realistic balance training as it supports the patient closer to the center of mass, the bicycle/saddle system allows notably faster don-on and don-off than the overhead harness system. Therefore, a patient receives longer actual training in a pre-set time period.
There is also a perceived safety advantage for the bicycle/saddle type BWSS. The MIT-Skywalker employs a split treadmill system which permits different tread speeds for each leg. The asymmetric speed programs focus on altering the step-length asymmetry via speed distortion (asymmetric split-belt speeds). A risk analysis includes the potential that a person using the overhead harness system might land a foot on the opposite tread which is undesirable. This is less of a concern on the bicycle/saddle system that centers the patient at all times $[30,37]$. Figure 9 shows images of the three tested cases and one can note that subjects are centered all the time when employing the bicycle/saddle BWS. Subjects reported some level of discomfort but overall reported that it was more comfortable to walk on the bicycle/saddle BWS than the overhead BWS one.

Last but not least, the bicycle/saddle support system allows us to install the system in most clinics without major space alterations. In the US, regulations require a minimum ceiling height of $8 \mathrm{ft}(2.4 \mathrm{~m})$ and many 

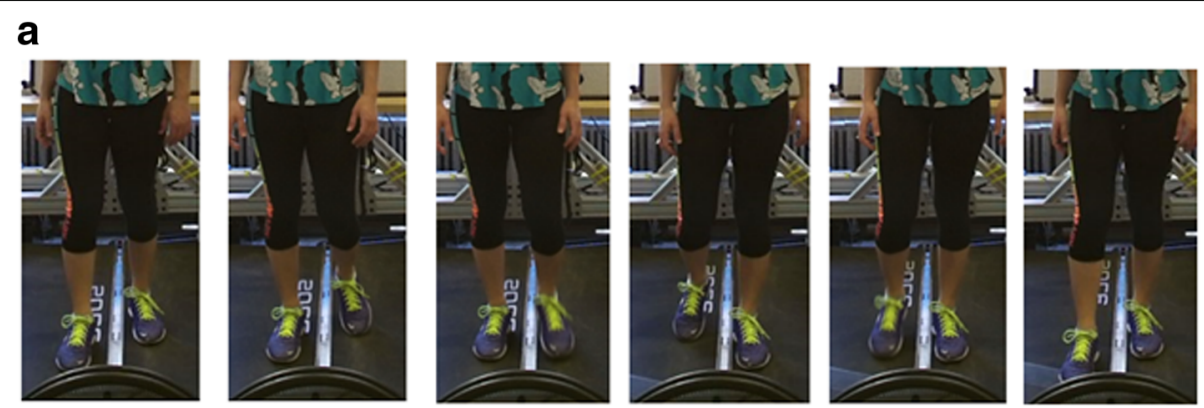

b
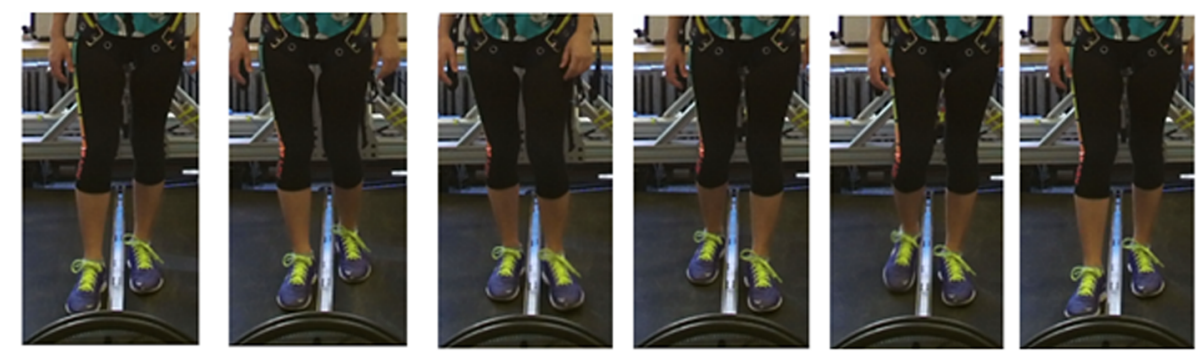

C
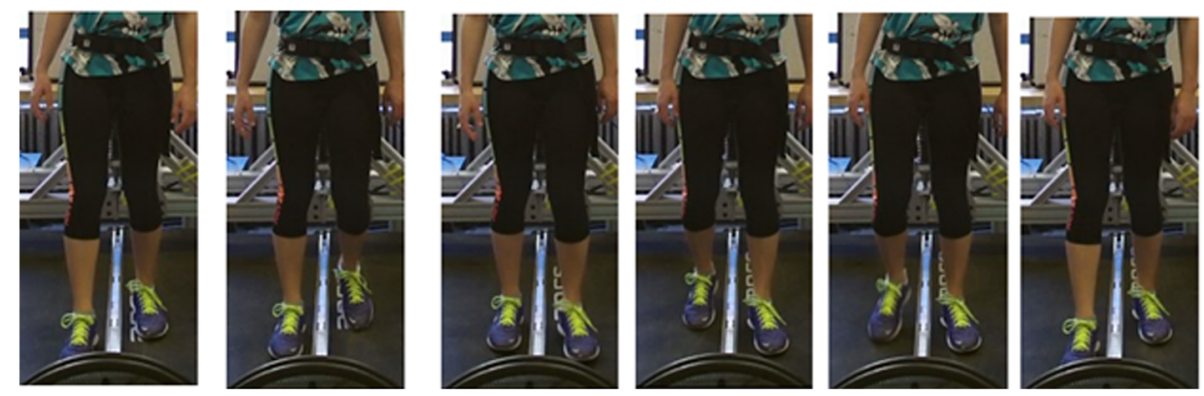

Fig. 9 Compare different BWS. (a) Without BWS; (b) With Harness; (c) MIT-Skywalker

devices, including many overhead BWS systems, require major space alterations even in code compliant facilities.

\section{Conclusion}

In this paper we presented a comparison between two forms of BWS used by healthy subjects. We compared the "traditional" overhead harness with the bicycle/saddle system. Both cases presented different COM and shoulderspine values when compared to the unsupported case. The bicycle/saddle system had the highest values for the mediolateral inclination and better centered the patient to the split treadmill, hence enhancing safety. The overhead harness BWS showed the smallest inclination for all the speeds, which might be adequate for rhythmic training but limits its potential for balance training. We believe our results may be transferable to any other devices employing simple BWS systems. We are presently 1) optimizing the bicycle/saddle seat shape to improve comfort, 2) developing a closed-loop control to adjust saddle support during training, and 3) planning clinical trials to assess whether our approach will lead to better results when compared to those produced using usual care.

\section{Abbreviations}

BWSTT: Body weight supported treadmill training; COM: Center of mass; RCTs: Randomized controlled trials;

\section{Acknowledgements}

The authors would like to thank study participants.

\section{Funding}

This work was partially supported by CNPq (process 200,282/2015-8) and FAPEMIG (process TEC-APQ-01665-14).

\section{Availability of data and materials}

There are no additional files.

\section{Authors' contributions}

RSG carried out the experiments, collected results, performed data analysis, and wrote the manuscript; HIK conceived the study, performed data analysis, and contributed to the writing of the manuscript and of the revision. Both authors read and approved the final manuscript.

\section{Ethics approval and consent to participate}

The study was approved by the MIT Committee on the Use of Humans as Experimental Subjects (COUHES), and written informed consent was

obtained from each participant. 


\section{Consent for publication}

All authors read and approved the final manuscript.

\section{Competing interests}

H. I. Krebs is a co-inventor in several MIT-held patents for robotic therapy. He holds equity positions in Bionik Laboratories, the company that manufactures this type of technology under license to MIT.

\section{Publisher's Note}

Springer Nature remains neutral with regard to jurisdictional claims in published maps and institutional affiliations.

\begin{abstract}
Author details
${ }^{1}$ Federal University of Uberlândia/Brazil, School of Mechanical Engineering, Av. João Naves de Ávila 2121 Campus Santa Monica CX 593, Uberlândia, MG CEP 38408-100, Brazil. ' ${ }^{2}$ Mechanical Engineering Department, The Eric P. and Evelyn E. Newman Laboratory for Biomechanics and Human Rehabilitation, Massachusetts Institute of Technology - MIT, Boston, USA. ${ }^{3}$ Mechanical Engineering Department, Principal Research Scientist \& Lecturer MIT, Room 3-137 Massachusetts Institute of Technology, 77 Massachusetts Avenue, Cambridge, MA 02139-4307, USA. ${ }^{4}$ Neurology Department, University of Maryland, School of Medicine, Baltimore, USA. ${ }^{5}$ Mechanical Science and Bioengineering Department, Osaka University, Suita, Japan. ${ }^{6}$ Fujita Health University, School of Medicine, Toyoake, Japan. ${ }^{7}$ Newcastle University, Institute of Neuroscience, Newcastle, UK. ${ }^{8}$ Loughborough University, The Wolfson School of Engineering, Loughborough, UK.
\end{abstract}

\section{Received: 4 October 2016 Accepted: 30 August 2017}

Published online: 06 September 2017

\section{References}

1. Mozaffarian D, Benjamin EJ, Go AS, Arnett DK, Blaha MJ, Cushman M, Das SR, de Ferranti S, Després J-P, Fullerton HJ, Howard VJ, Huffman MD, Isasi CR, Jiménez MC, Judd SE, Kissela BM, Lichtman JH, Lisabeth LD, Liu S, Mackey RH, Magid DJ, McGuire DK, Mohler ER III, Moy CS, Muntner P, Mussolino ME, Nasir K, Neumar RW, Nichol G, Palaniappan L, Pandey DK, Reeves MJ, Rodriguez CJ, Rosamond W, Sorlie PD, Stein J, Towfighi A, Turan TN, Virani SS, Woo D, Yeh RW, Turner MB; on behalf of the American Heart Association Statistics Committee and Stroke Statistics Subcommittee. Heart disease and stroke statistics - 2016 update: a report from the American Heart Association. Circulation. 2016;133:000-000.

2. Edward SC, Chandramouli K, Sandeep PK. Emerging treatments for motor rehabilitation after stroke. Neurohospitalist. 2015:5(2):77-88.

3. Sommerfeld DK, Eek EU, Svensson AK, Holmqvist LW, von Arbin MH. Spasticity after stroke its occurrence and association with motor impairments and activity limitations. Stroke. 2004;35(1):134139.

4. Marc F. New approaches to neuroprotective drug development. Stroke. 42: S24-S27, January 2011. PMID: 21164111

5. Schaechter JD. Motor rehabilitation and brain plasticity after hemiparetic stroke. Prog Neurobiol. 2004;73(1):61.

6. Dobkin B, Apple D, Barbeau H, Basso M, Behrman A, Deforge D, Ditunno J, Dudley G, Elashoff R, Fugate L, Harkema S, Saulino M, Scott M, and the Spinal Cord Injury Locomotor Trial (SCILT) Group. Weight-supported treadmill vs over-ground training for walking after acute incomplete SCl. Neurology. 2006;66(4):484-93.

7. Sullivan KJ, Knowlton BJ, Dobkin BH. Step training with body weight support: effect of treadmill speed and practice paradigms on poststroke locomotor recovery. Arch Phys Med Rehabil. 2002;83(5):683-91.

8. Duncan PW, Sullivan KJ, Behrman AL, Azen SP, Wu SS, Nadeau SE, Dobkin $\mathrm{BH}$, Rose DK, Tilson JK, Cen S. Body weight supported treadmill rehabilitation after stroke. N Engl J Med. 2011;364(21):20262036.

9. Harkema SJ. Neural plasticity after human spinal cord injury: application of locomotor training to the rehabilitation of walking. Neuroscientist. 2001;7(5): 455-68.

10. Hesse S, Bertelt C, Jahnke MT, Schaffrin A, Baake P, Malezic M, Mauritz KH. Treadmill training with partial body weight support compared with physiotherapy in nonambulatory hemiparetic patients. Stroke. 1995;26(6): 976-81. PMID: 7762049

11. Catherine MS, Nadina BL. Physiotherapy treatment for stroke patients: a survey of current practice. Physiother Theory Pract. 1996;12(2):8796.
12. Ingrid $G L$, van de Port SWD, Eline $L$, Gert K. Effects of exercise training programs on walking competency after stroke: a systematic review. Am J Phys Med Rehabil. 2007;86(11):935951.

13. Ichiro M, Hiroki CT, Ichiro S, Hideo E, Ichiro O, Ikuo K, Yoshio T, Tsunehiko S, Toshio Y, Kisou K. Cortical mapping of gait in humans: a near-infrared spectroscopic topography study. Neurolmage. 2001;14(5):11861192.

14. Christian E, Helen D, Heidi J-B, Derick W, Marko B, Jonathan C, Claire G, Udo K, Stefan R, Franz F, Paul M. Brain activity changes associated with treadmill training after. Stroke. 2009;40(7):2460-7. PMID: 19461018

15. Colombo G, Joerg M, Schreier R, Dietz V, others. Treadmill training of paraplegic patients using a robotic orthosis. J Rehabil Res Dev. 2000;37(6): 693-700.

16. Veneman JF, Kruidhof R, Hekman EE, Ekkelenkamp R, Van Asseldonk EH, Van Der Kooij H. Design and evaluation of the LOPES exoskeleton robot for interactive gait rehabilitation. Neural Syst Rehabil Eng IEEE Trans. 2007;15(3): 379-86.

17. Banala SK, Agrawal SK, Scholz JP. Active leg exoskeleton (ALEX) for gait rehabilitation of motor-impaired patients. Rehabilitation robotics, 2007. ICORR 2007. In: IEEE 10th international conference on; 2007. p. 401-7.

18. Uhlenbrock D, SarkodieGyan T, Reiter F, Konrad M, Hesse S. Development of a servo-controlled gait trainer for the rehabilitation of non-ambulatory patients. Biomed Tech. 1997;42(7-8):196-202.

19. Hesse $S$, Uhlenbrock $D$, others. A mechanized gait trainer for restoration of gait. J Rehabil Res Dev. 2000;37(6):701-8.

20. Schmidt H, Werner C, Bernhardt R, Hesse S, Krüger J. Gait rehabilitation machines based on programmable footplates. J Neuroeng Rehabil. 2007;4(1):2.

21. Hesse $\mathrm{S}$, Waldner A, Tomelleri $\mathrm{C}$. Innovative gait robot for the repetitive practice of floor walking and stair climbing up and down in stroke patients. J NeuroEngineering Rehabil. 2010;7:30.

22. Husemann B, Müller F, Krewer C, Heller S, Koenig E. Effects of locomotion training with assistance of a robot-driven gait orthosis in hemiparetic patients after stroke a randomized controlled pilot study. Stroke. 2007;38(2): 349-54.

23. Mayr A, Kofler M, Quirbach E, Matzak H, Fröhlich K, Saltuari L. Prospective, blinded, randomized crossover study of gait rehabilitation in stroke patients using the Lokomat gait orthosis. Neurorehabil Neural Repair. 2007;21(4):307-14.

24. Hesse S, Uhlenbrock D, Sarkodie-Gyan T. Gait pattern of severely disabled hemiparetic subjects on a new controlled gait trainer as compared to assisted treadmill walking with partial body weight support. Clin Rehabil. 1999:13(5):401-10.

25. Hesse S, Werner C, Uhlenbrock D, Frankenberg SV, Bardeleben A, BrandlHesse B. An electromechanical gait trainer for restoration of gait in hemiparetic stroke patients: preliminary results. Neurorehabil Neural Repair. 2001;15(1):39-50.

26. Pohl M, Werner C, Holzgraefe M, Kroczek G, Wingendorf I, Hoölig G, Koch R, Hesse S. Repetitive locomotor training and physiotherapy improve walking and basic activities of daily living after stroke: a single-blind, randomized multicentre trial (DEutsche GAngtrainerStudie, DEGAS). Clin Rehabil. 2007; 21(1):17-27.

27. Hidler J, Nichols D, Pelliccio M, Brady K, Campbell DD, Kahn JH, Hornby TG. Multicenter randomized clinical trial evaluating the effectiveness of the Lokomat in subacute stroke. Neurorehabil Neural Repair. 2009;23(1):5-13.

28. Hornby TG, Campbell DD, Kahn JH, Demott T, Moore JL, Roth HR. Enhanced gait-related improvements after therapist- versus robotic-assisted Locomotor training in subjects with chronic stroke a randomized controlled study. Stroke. 2008;39(6):1786-92.

29. Susko T, Krebs HI, MIT-Skywalker. A novel environment for neural gait rehabilitation. In: Biomedical robotics and Biomechatronics (2014 5th IEEE RAS \& EMBS international conference on); 2014. p. 677-82.

30. Susko T, Krebs HI. MIT-Skywalker: a novel gait Neurorehabilitation robot for stroke and cerebral palsy. In: IEEE transactions on neural systems and rehabilitation engineering; 2016.

31. Krebs HI, Michmizos K, Susko T, Lee H, Roy A, Hogan N. Beyond human or robot administered treadmill training. In: Neurorehabilitation Technology, Second Edition. Springer International Publishing; 2016. p. 409-433.

32. Krebs HI, Hogan N, Aisen ML, Volpe BT. Quantization of continuous arm movements in humans with brain injury. Proc Natl Acad Sci. 1999;96: 4645-4649.

33. Hogan N, Doeringer JA, Krebs HI. Arm movement control is both continuous and discrete, cognitive studies; Bull Jpn Cogn Sci Soc. 1999;6:3: 254-273. 
34. Rohrer B, Fasoli S, Krebs HI, Volpe B, Frontera WR, Stein J, Hogan N. Submovements grow larger, fewer, and more blended during stroke recovery. Mot Control. 2004;8:472-83.

35. Dipietro L, Krebs HI, Volpe BT, Stein J, Bever C, Mernoff ST, Fasoli SE, Hogan N. Learning, not adaptation, characterizes stroke motor recovery: evidence from kinematic changes induced by robot-assisted therapy in trained and untrained task in the same workspace. IEEE Trans Neural Syst Rehabil Eng. 2012;20(1):48-57.

36. Levy-Tzedek S, Krebs HI, Song D, Hogan N, Poizner H. Non-Monotonicity on a Spatio-temporally defined cyclic task: evidence of two movement types? Exp Brain Res. 2010;202(4):733-46.

37. Susko TG. MIT Skywalker: a novel robot for gait rehabilitation of stroke and cerebral palsy patients. Cambridge: Thesis, Massachusetts Institute of Technology; 2015.

38. Susko T, Krebs HI. IR vision system for the estimation of gait phase of the MIT-Skywalker, in northeast bioengineering conference (NEBEC), 2014 40th annual; 2014. p. 1-2.

39. Lim D, Kim C, Jung H, Jung D, Chun K. Use of the Microsoft Kinect system to characterize balance ability during balance training. Clin Interv Aging. 2015; 10:1077-83.

40. Mentiplay BF, Perraton LG, Bower KJ, Pua Y-H, McGaw R, Heywood S, Clark RA. Gait assessment using the Microsoft Xbox one Kinect: concurrent validity and inter-day reliability of spatiotemporal and kinematic variables. J Biomech. 2015;48:2166-70.

41. van Diest M, Stegenga J, Wörtche HJ, Postema K, Verkerke GJ, Lamoth CJC. Suitability of Kinect for measuring whole body movement patterns during exergaming. J Biomech. 2014:47:2925-32.

42. Xu X, McGorry RW, Chou L-S, J-h L, C-chi C. Accuracy of the Microsoft Kinect for measuring gait parameters during tradmill walking. Gait Posture. 2015; 42:145-51.

43. Leightley D, Yap MH, Coulson J, Barnouin Y, McPhee JS. Benchmarking human motion analysis using Kinect one: an open source dataset. In: Proceedings of APSIPA; 2015

44. Woolford K. Defining accuracy in the use of Kinect v2 for exercise monitoring. In: MOCO'15 Proceedings of the $2^{\text {nd }}$ international workshop on movement and computing; 2015. p. 112-9.

45. Ahmed F, Paul PP, Gavrilova ML. Kinect-based gait recognition using sequences of the most relevant joint relative angles. J WSCG. 2015;23: 147-56.

46. Cippitelli E, Gasparrini S, Spinsante S, Gambi E. Kinect as a tool for gait analysis: validation of a real-time joint extraction algorithm working in side view. Sensors. 2015;15:1417-34

47. Springer S, Seligmann GY. Validity of the Kinect for gait assessment: a focused review. Sensors. 2016;16:194-207.

48. Ahmed F, Tse E, Gavrilova, ML. Kinect-based action recognition in a meeting room environment. Intell Inf Database Syst. 2015;9012:92-101.

49. Kale MR. Human gait characterization using Kinect, Bachelor thesis. 2015.

50. Yang L, Dong LZH, Alelaiwi A, El Saddik A. Evaluating and improving the depth accuracy of Kinect for windows v2. IEEE Sensors J. 2015;15(8):42754285.

51. Zhu Y, Zhao Y, Zhu S-C. Undertanding tools: task-oriented object modeling, learning and recognition. IEEE Conf Comput Vis Pattern Recognit. 2015: 2855-64.

52. Orendurff MS, Segal AD, Klute GK, Berge JS, Rohr ES, Kadel NJ. The effect of walking speed on center of mass displacement. J Rehabil Res Dev. 2004;41: 829-34

53. Millslagle D, Levy M, Matack N. Comparative kinematic measures of treadmill running with or without body weight support in runners. J Sports Sci Med. 2005;4:583-9.

54. Karthikbabu S, Rao BK, Manikandan N, Solomon JM, Chakrapani M, Nayak A. Role of trunk rehabilitation on trunk control, balance and gait in patients with chronic stroke: a pre-post design. Neurosci Med. 2011;2:61-7.

55. Jung K-S, Cho H-Y, In T-S. Trunk exercises performed on an unstable surface improve trunk muscle activation, postural control, and gait speed in patients with stroke. J Phys Ther Sci. 2016:28:940-4.

56. Karthikbabu S, Nayak A, Vijayakumar K, Misri ZK, Suresh BV, Ganesan S, Joshua AM. Comparison of physio ball and plinth trunk exercises regimens on trunk control and functional balance in patients with acute stroke: a pilot randomized controlled trial. Clin Rehabil. 2011;25(8):709-19.
57. Duysens J, Verheyden G, Massaad F, Meyns P, Smits-Engelsman B, Jonkers I. Rehabilitation of gait and balance after CNS damage. Chapter 18, Oxford Textbook of Neurorehabilitation. UK: Oxford University Press; 2015. p. 211-223.

58. Karthikbabu S, Chakrapani M, Ganeshan S, Raskshith KC, Nafeez S, Prem V. A review on assessment and treatment of the trunk in stroke: a need or luxury. Neural Regen Res. 2012;7(25):1974-1977.

59. Rai RK, Arora L, Sambyal S, Arora R. Efficacy of trunk rehabilitation and balance training on trunk control, Balance and Gait in Post Stroke Hemiplegic Patients: A Randomized Controlled Trial IOSR J Nurs Health Sci. 2014;3(3):27-31.

60. Swinnen E, Baeyens JP, Pintens S. Niewnhoven JV, Ilsbroukx S, Buyl R, Ron C, Goossens M, Meeusen R, Kerckhofs E. Trunk kinematics during walking in persons with multiple sclerosis: The influence of body weight support. NeuroRehabilitation. 2014;34:731-740.

61. Jahn K, Zwergal A, Schniepp R. Gait disturbance in old age. Dtsh Arztebl Intr. 2010;107(17):306-16

62. Finch L, Barbeau H, Arsenault B. Influence of body weight support on normal human gait: development of a gait retraining strategy. Phys Ther. 1991;71(11):842-855

63. Fischer $A G$, Wolf $A$. Assessment of the effects of body weight unloading on overground gait biomechanical parameters. Clin Biomech. 2015;30:454-61.

64. Sousa CO, Barela JA, Prado-Medeiros CL, Salvini TF, Barela AMF. The use of body weight support on ground level: an alternative strategy for gait training of individuals with stroke. J Neuroeng Rehabil. 2009;6:43.

65. Vallery H, Lutz P, von Zitzewitz J, Rauter G, Fritschi M, Everarts C, Ronsse R, Curt A, Bolliger M. Multidirectional transparent support for Overground gait training. In: IEEE international conference on rehabilitation robotics; 2013.

66. Pennycott A, Wyss D, Vallery H, Riener R. Effects of added inertia and body weight support on lateral balance control during walking. In: IEEE international conference on rehabilitation robotics; 2011.

67. Kataoka N, Hirai H, Yoshikawa F, Kuroiwa A, Nagakawa Y, Watanabe E, Ninomaru Y, Saeki Y, Uemura M, Miyazaki F, Hamilton T, Nakat H, Nishi T, Naritomi $\mathrm{H}$, Krebs HI. Effects of partial body weight support and functional electrical stimulation on gait characteristics during treadmill exercise: pros and cons of saddle-seat-type body weight support. In: 15th IEEE Int Conf Rehabil Robot 2017;381-386. doi: 10.1109/ICORR.2017.8009277.

68. Hidler JM, Stienen AHA, Vallery H. Robotic devices for Overground gait and balance training, chapter 23. Neurorehabilitation Technology: Springer; 2016.

\section{Submit your next manuscript to BioMed Central and we will help you at every step:}

- We accept pre-submission inquiries

- Our selector tool helps you to find the most relevant journal

- We provide round the clock customer support

- Convenient online submission

- Thorough peer review

- Inclusion in PubMed and all major indexing services

- Maximum visibility for your research

Submit your manuscript at www.biomedcentral.com/submit 